\title{
Ni discernir podía
}

\section{Margo Glantz}

\section{1.-}

De mi reciente libro Y pormirarlo todo, nada veía, dijo Luis Bugarini en un artículo en la revista Nexos, "Glantz se arriesga felizmente con una entrega que descolocará a los lectores menos receptivos a ejercicios escriturales libérrimos, si bien ganará la aceptación de quienes celebran, por encima de todo, que se pongan en entredicho los modelos literarios habituales con la intención de sintonizarlos con los tiempos del mundo. Kenneth Goldsmith, que ha defendido la condición del escritor como 'archivista', celebraría esta entrega de Glantz, hermanada con su Wasting Time on the Internet (2016) y, de manera genérica, con un modo de ejercer la literatura como si se tratase de un juego para endulzar el paso del tiempo. Sin gravedad, sin nostalgias, lejos de cualquier realismo cancerígeno. En esta búsqueda, los grandes temas del pasado quedan tal como los dejaron sus cultivadores y se abre cancha a un modo de celebrar la vida con toda su fugacidad, a partir de las posibilidades creativas que ofrece la catalogación, el culto por el 'archivismo', y cualquier otro método posible de lograr taxonomías por el gusto de inaugurarlo".

\section{2.-}

Y sin descartar una fuerte dosis de narcisismo, cito largamente porque me permite iniciar este texto (también narcisista) cuestionando el fenómeno de las redes sociales, a partir de una pregunta que me hice y que originó y meduló mi libro:

Al leer las noticias que aparecen en el tuiter o lo que los usuarios escriben en el facebook ¿cómo decidir qué es lo más importante? ¿Que el 31 de enero de 2018 apareciera en el cielo una enorme luna azul, ensangrentada, que al conocer a Felice, su futura prometida, Kafka escribiera en su Diario: Un rostro vacío que llevaba abiertamente su vacío; que el ajolote mexicano sea el único animal capaz de regenerar extremidades, órganos y tejido; que El Cabo, en Sudáfrica, sea la primera ciudad en el mundo que se quedará totalmente sin agua; que unos científicos hayan logrado crear orejas para cinco niños que sufrían de una malformación hereditaria, que Charlie Sheen sea portador del VHS; que las calles de Coyoacán tengan encendidas o apagadas las luces; que se haga justicia en Ayotzinapa; que la deuda pública mexicana sea incontrolable, que haya rehenes en Mali; que se legalice o no la mariguana; que 
hayan ganado Trump o Clinton o Macri o Scioli, que la palabra impeachment no tenga verdadera traducción al español, que se siga lavando dinero y vendiendo armas, que los narcorridos se prohiban, que se decrete la ley de transparencia (dudosa), que un tigre ande suelto por las calles de Acapulco, que Lenin haya entrado a San Petersburgo en vísperas de la Revolución Rusa, que ya se pueda comer salmón transgénico; que desde hace cuatro años nieve en el Sahara; que las maletas inteligentes ya sean una realidad; que haya estados de excepción; que policías de Estados Unidos hayan matado a más de mil personas indefensas durante 2015, que el plástico, así como las redes sociales, haya sido benéfico y ahora contamine; que Marilyn Monroe se haya luxado un tobillo....?

\section{3.-}

¿Qué podremos deducir de este ejercicio de acumulación, de almacenamiento de noticias diversas que se conjuntan en un solo espacio? ¿Cómo retener y aún más entender ese bombardeo de datos tan fugaces, tan perecederos, tan evanescentes, tan huidizos? Lo más grave: ¿cómo jerarquizar esa información? ¿Cómo descartar lo que es aparentemente trivial de lo que aparece unido sin mediar ninguna reflexión a los acontecimientos más terribles? ¿Cómo detenerse y aquilatar esa proliferación de discursos en las redes sociales que nos hacen pensar en un mundo en donde todos hablan y ninguno escucha? ¿Una nueva Torre de Babel? ¿Sería posible entender ese fenómeno acudiendo de nueva cuenta a la ya trillada y aun manoseada frase de Hannah Arendt sobre la banalidad del mal?

\section{4.-}

Pensé que podría dar cuenta de ello recurriendo al centón, una técnica literaria muy frecuentada en la literatura griega y latina -y más tarde en el Renacimiento y el Barroco- del latín cento, ōnis, proveniente del griego $\kappa \dot{v} v \tau \rho \omega v$ "pieza hecha de retales", que designa también una obra literaria compuesta de retazos o fragmentos de otras obras y autores y, que en el caso de las redes sociales, colectivas y en gran medida anónimas, permite difundir, como si fueran aforismos, textos de nuestros escritores favoritos y lograr quizá en los casos excepcionales que el tuitero se convierta en un poeta japonés: ¿quién que es quién no intenta ser ingenioso, transgresor y pergeñar con los antiguos 140 caracteres (con espacios) maravillosos haikus?

\section{5.-}

Y no solo eso, reiterar que, como escribí en alguna parte, el ejercicio del tuiteo nos autoriza a caer de bruces en un narcisismo flagrante sin que los parámetros tradicionales de la modestia o la falsa modestia nos detengan ni ruboricen.

\section{6.-}

Este inventario, esta colección de frases breves, esta relación de acontecimientos relacionados con muy diversos ámbitos del diario acontecer muestra de manera flagrante y acumulativa el renacimiento de los fascismos, el cambio climático, la extinción de las especies, el feminicidio, el narcotráfico, la corrupción, la impunidad, los espacios interplanetarios, nuevos descubrimiento científicos, el Me too, noticias semejantes a las que coleccionó Ripley y ¿por qué no? algunas maravillas. 


\section{7.-}

Y quizá también una autobiografía pulverizada y una especie de ready made literario.

\section{8.-}

Pensé sobre todo que una colección de textos provenientes en su mayoría del tuiter y unificados literariamente mediante el montaje, sin utilizar cursivas, sólo escasos signos de puntuación (como el punto y coma, los puntos suspensivos, las interrogaciones), provocaría tal vez en los lectores una distancia crítica, a pesar de su ambigüedad.

\section{9.-}

Y unos versos del Primero sueño de Sor Juana Inés de la Cruz aclaraban de cierto modo mi propósito: "Y por mirarlo todo/ nada veía/ y ni discernir podía...", momento de inflexión del poema en que la monja jerónima, "bota la facultad intelectiva/ en tanta, $\tan$ difusa/ incomprensible especie que miraba/ desde el un eje en que librada estriba/ la máquina voluble de la Esfera...: se detiene a mitad del camino para intenta ver y no sólo mirar. 
